\title{
Análise da Incidência de Manifestações Patológicas em Edificações de Concreto Armado
}

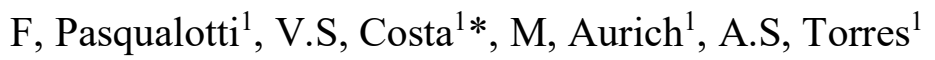 \\ *Autor de Contacto: vitoriascosta@yahoo.com.br \\ ${ }^{1}$ Programa de Pós-graduação em Arquitetura e Urbanismo, Universidade Federal de Pelotas, Pelotas, Brasil.
}

\begin{abstract}
RESUMEN
Las estructuras de hormigón armado están diseñadas para una vida útil mínima de 50 años. Debido a procesos naturales, como el envejecimiento y la degeneración, asociados a la falta o ineficiencia de los procesos de mantenimiento de la estructura, surgen manifestaciones patológicas. El presente estudio tuvo como objetivo verificar la existencia de una relación entre la aparición de manifestaciones patológicas y la antigüedad de los edificios. Se desarrolló una revisión de la literatura, en dos conjuntos de edificios: el primero con una edad de uso igual o superior a 30 años y el segundo con una edad menor a los 30 años. Se encontró que, con el aumento de la edad del edificio, aumenta la complejidad de las manifestaciones patológicas.
\end{abstract}

Palabras clave: hormigón armado, manifestaciones patológicas, vida útil.

\section{RESUMO}

As estruturas de concreto armado são projetadas para uma vida útil mínima de 50 anos. Entretanto, devido à processos naturais, como o envelhecimento e degeneração, associados à falta ou ineficiência dos processos de manutenção das estruturas, surgem as manifestações patológicas. $\mathrm{O}$ presente estudo teve como objetivo verificar a existência de uma relação entre o surgimento das manifestações patológicas com a idade de uso da edificação. Para tanto, foi desenvolvido um estudo de revisão de literatura, em dois conjuntos de edificações: o primeiro com idade de uso igual ou superior a 30 anos e o segundo com idade inferior a 30 anos. Verificou-se que com o aumento da idade de uso da edificação, ocorre um aumento na complexidade das manifestações patológicas.

Palavras-chave: concreto armado, manifestações patológicas, vida útil.

\section{ABSTRACT}


Reinforced concrete structures are designed for a minimum service life of 50 years. Due to natural processes, such as aging and degeneration, associated with the lack or inefficiency of the structure's maintenance processes, pathological manifestations arise. The present study aimed to verify the existence of a relationship between the appearance of pathological manifestations and the age of the buildings. Thus, a literature review study was developed, in two sets of buildings: the first with an age of use equal to or greater than 30 years and the second with an age below 30 years. It was found that with the increase in the age of use of the building, there is an increase in the complexity of pathological manifestations.

Keywords: Reinforced concrete; pathological manifestations; lifespan.

\section{INTRODUÇÃO}

O concreto armado é uma das técnicas construtivas mais tradicionais no emprego em elementos estruturais, devido à sua versatilidade e durabilidade. A técnica foi introduzida no Brasil na primeira metade do século XX e algumas de suas características como a segurança, custo e mão de obra tornaram a utilização do material bastante conveniente (Santos, 2008).

Apesar de existir um grande investimento tecnológico no desenvolvimento de concretos mais duráveis e resistentes, através de aditivos químicos e de adições, como a cinza volante, sílica ativa, fibras entre outros. De acordo com Beber (2003), o concreto possui um processo de fabricação de natureza praticamente artesanal, o que implica em pequenas variações em sua composição possam conduzir à produção de concretos excepcionalmente duráveis ou extremamente vulneráveis.

Nas edificações, as manifestações patológicas são os sinais externos e sintomas apresentados quando existe algum problema em sua integridade (Tutikian et. al, 2013). Algumas vezes esses sinais externos podem demorar para se manifestar e outras podem ser imperceptíveis aos leigos.

Os processos de envelhecimento e degeneração das estruturas de concreto são naturais e inevitáveis (Beber, 2003), entretanto, conforme a Fédération Internationale du Betón (FIB, 1999), a preocupação não está relacionada à degeneração propriamente dita, mas sim com seu desenvolvimento e com as condicionantes que determinam sua evolução. Tal fator é reforçado pelo fato de existirem normas técnicas que estabelecem o prazo para o qual a estrutura deve manter sua integridade.

De acordo com a NBR 15575 (ABNT, 2013), que estabelece os requisitos básicos de desempenho para edificações habitacionais, as estruturas devem ser projetadas e construídas de modo que, sob as condições ambientais previstas em projeto, conservem sua segurança, estabilidade e aptidão de serviço, durante o prazo correspondente à vida útil de projeto, sendo esse, o período no qual se mantêm as características das estruturas de concreto sem que necessitem de intervenções significativas. No caso de estruturas, como os elementos de fundação, pilares, vigas, lajes, entre outros, a norma estabelece uma vida útil mínima de 50 anos. Ademais, a NBR 6118 (ABNT, 2014), estabelece os critérios gerais para projetos de estruturas de concreto armado, indica que o conceito de vida útil pode ser aplicado à estrutura como um todo ou às suas partes, dessa forma, determinadas partes da estrutura podem requerer considerações especiais, com um valor de vida útil diferente, como por exemplo os aparelhos de apoio e as juntas de movimentação.

Durante a vida útil da estrutura, é recorrente a ocorrência de alterações no uso e no entorno da edificação, podendo, nesses casos, ser criado um ambiente mais agressivo ou haver um acréscimo na carga da estrutura, condições diferentes e que não conseguem ser previstas durante a elaboração do projeto. Além disso, em diversos casos, as edificações não passam por processos de manutenções preventivas, ou sofrem manutenções ineficientes, conforme citado por Silva et. al (2016) e Araújo et. al (2010). 
Devido aos itens supracitados, como o envelhecimento e degradação natural da estrutura, a alta variabilidade do processo de execução do concreto, a alteração do ambiente para o qual a edificação foi projetada e do seu uso, como a ausência ou ineficiência dos processos de manutenções, é criado um ambiente propício para o surgimento de manifestações patológicas nas estruturas. Conforme Couto et. al (2013), é interessante ressaltar que os danos apresentados nos elementos estruturais são do tipo evolutivo, ou seja, em maior ou menor prazo de tempo, poderão comprometer sua estabilidade.

O presente estudo teve como objetivo identificar, por meio de revisão de literatura, as manifestações patológicas de maior incidência em elementos de concreto armado de dois conjuntos de edificações: o primeiro com idade de uso igual ou superior há 30 anos e o segundo com idade inferior há 30 anos. Buscando-se verificar a existência de uma relação entre o surgimento das manifestações patológicas com a idade de uso da edificação.

\section{REFERENCIAL TEÓRICO}

Patologia é um termo utilizado em diversas áreas da ciência, sendo utilizado tanto para a área da Medicina quanto para outras áreas do conhecimento humano, como a Engenharia. Tem sua origem no grego, em que deriva dos termos pathos, que significa sofrimento, doença e logos, que quer dizer ciência, estudos (Sena et. al, 2020). Ainda, de acordo com os autores, o termo Patologia, em termos gerais, corresponde ao estudo das doenças, representando um estado ou condição anormal, cujas causas podem ser conhecidas ou desconhecidas.

$\mathrm{Na}$ engenharia civil, designa-se Patologia das Estruturas a área de estudo sobre as origens, formas de manifestação, consequências e mecanismos de ocorrência das falhas dos sistemas de degradação das estruturas. As manifestações patológicas decorrem do desempenho insatisfatório das edificações, quando confrontadas com as finalidades para as quais foram projetadas, sendo provenientes de falhas involuntárias e casos de imperícias, o conjunto desses fatores provocam a deterioração das estruturas, podendo ser decorrentes do seu envelhecimento natural, de acidentes e até de irresponsabilidades profissionais, quando utilizados materiais fora de especificações (Souza et. al, 2009).

\subsection{Métodos de Diagnóstico}

O diagnóstico, quando relacionado à problemas patológicos, corresponde a todo o processo que possa explicitar cientificamente os fenômenos ocorridos em uma construção onde acontecem manifestações patológicas (Lopes, 2019). De acordo com Tutikian e Pachecho (2013), o diagnóstico é o responsável pela redução no número de dúvidas, tendo em vista que sempre haverá um grau de incerteza quanto ao diagnóstico, cuja eficácia só poderá ser confirmada pela resposta satisfatória ao tratamento prescrito.

Existem diversas metodologias e procedimentos para compreender e determinar o estado de conservação das estruturas de concreto armado. Entre as mais utilizadas no diagnóstico das manifestações patológicas, podem ser citadas a inspeção visual, o levantamento do histórico da estrutura, os ensaios destrutivos, ou seja, aqueles que necessitam da extração de corpos de prova testemunho, e os não destrutivos, que são aqueles que não alteram de forma permanente as propriedades físicas, mecânicas ou químicas do elemento estrutural, como os ensaios de detecção magnética de armaduras, ultrassonografia, resistividade elétrica, potencial de corrosão, profundidade de carbonatação, entre outros (Passos et. al, 2019).

\subsection{Manifestações Patológicas em Concreto Armado}


A NBR 6118 (ABNT, 2014), em seu item 6.3 especifica os mecanismos preponderantes de envelhecimento e deterioração das estruturas de concreto armado. Ainda de acordo com a NBR 6118 (ABNT, 2014), os principais mecanismos de deterioração relativos ao concreto são: lixiviação, expansão por sulfato e a reação álcali-agregado; já para a deterioração da armadura estão destacados a despassivação por carbonatação, por ação de cloretos e aqueles relacionados às ações mecânicas:

Lixiviação é o mecanismo responsável por dissolver e carregar compostos hidratados da pasta de cimento por ação das águas. Para sua prevenção a norma recomenda o controle da fissuração e a utilização de produtos hidrófugos. Ainda, de acordo com Sena et. al (2020), a lixiviação é o mecanismo que provoca o surgimento de manchas de eflorescência, que são manchas brancas que se formam na superfície de estruturas de concreto causadas pelo contato com águas puras, ácidas, carbônico agressivas entre outras.

A despassivação por carbonatação ocorre devido a ação do gás carbônico da atmosfera sobre o aço da armadura. Para minimizar este efeito, a norma recomenda o adequado cobrimento das armaduras e o controle de fissuração, além de concretos com baixa porosidade.

A despassivação por ação de cloretos é causada pelo elevado teor do íon-cloro. Para minimizar este efeito são feitas as mesmas recomendações utilizadas na despassivação por carbonatação, além do uso de cimento composto com adição de escória ou material pozolânico. Umas das primeiras manifestações patológicas decorrentes da corrosão da armadura é o surgimento de manchas amarronzadas na superfície do concreto (Sena et. al, 2020).

As causas por ações mecânicas são devido a movimentações de origem térmica, impactos, ações cíclicas, retração, fluência e relaxamento. Para sua prevenção são necessárias medidas específicas, como barreiras protetoras, isolamentos isotérmicos, entre outros.

Sena et. al (2020), também traz manifestações patológicas recorrentes em estruturas de concreto armado, destacando as manchas de bolor e umidade, fissuras e o desplacamento do concreto. A seguir uma breve descrição da origem e prováveis causas das manifestações patológicas destacadas pelos autores.

O bolor é formado por colônias de fungos (microorganismos) que possuem como fonte de alimento compostos orgânicos. Seu surgimento decorre da presença de elevada umidade, proveniente do solo, de infiltrações, vazamentos entre outros, associados a ambiente com pouca ventilação e baixa incidência de radiação. Em casos mais graves, pode proporcionar o crescimento de vegetações em pequenas fissuras e juntas de dilatação, provocando a biodegradação do concreto, além da corrosão de armaduras.

As fissuras são manifestações patológicas que podem apresentar algo simples, como um desconforto estético, decorrentes da retração do concreto, ou indicar que algo grave está para acontecer, podendo, por exemplo, ser decorrentes de sobrecargas na estrutura. As principais causas de fissuras de sobrecarga estão relacionadas à flexão, torção, tração, perda de aderência, cortante e cargas concentradas nos elementos estruturais.

O desplacamento do concreto está associado à perda de aderência entre a armadura e o concreto, em alguns casos essa perda de aderência decorre da expansão das armaduras em função da corrosão do aço.

\section{METODOLOGIA}

O presente estudo corresponde a uma pesquisa de revisão bibliográfica, em que foi desenvolvida uma revisão da literatura existente sobre o tema patologias em estruturas de concreto armado. Foram selecionados diferentes estudos de casos que, de maneira direta ou indireta, apontam as manifestações patológicas identificas em elementos de concreto armado.

Como critério para a seleção dos trabalhos utilizados na revisão bibliográfica, foram limitadas as publicações entre os anos de 2010 e 2020 . A pesquisa teve como foco os artigos que apresentassem 
as manifestações patológicas identificadas exclusivamente em estruturas de concreto armado, sem que fosse limitado uma tipologia exclusiva para as edificações selecionadas.

Os estudos selecionados pelo método anterior foram divididos em dois grupos distintos, o primeiro deles com edificações que possuíam idade igual ou superior a 30 anos, de modo a verificar a existência de uma tendência no surgimento das manifestações patológicas nos elementos de concreto armado que já atingiram mais de metade da Vida Útil de Projeto, conforme estabelecido pela NBR 15575 (ABNT, 2013). O segundo grupo, com edificações de idade inferior a 30 anos, para identificar quais as manifestações patológicas são recorrentes em edificações consideradas jovens.

Entre os estudos selecionados foram catalogadas as manifestações patológicas apontadas pelos autores e os métodos de diagnóstico utilizados para sua identificação. Foi desenvolvido um comparativo das manifestações identificadas entre dois grupos de edificações distintos e do método de diagnóstico mais utilizado. Na tabela 1 está disposta uma síntese contendo os estudos de caso das edificações com idade superior a 30 anos, expondo o autor do estudo, a idade da edificação, a classificação ambiental conforme NBR 6118 (ABNT, 2014), além de um breve relato do trabalho, contendo os métodos de diagnósticos utilizados e as manifestações patológicas identificadas.

Tabela 1. Estudos de Caso com Idade Superior a 30 anos.

\begin{tabular}{|c|c|c|c|c|}
\hline Autor & $\begin{array}{c}\text { Idade da } \\
\text { Edificação }\end{array}$ & $\begin{array}{c}\text { Classificação } \\
\text { Ambiental }\end{array}$ & $\begin{array}{l}\text { Método de } \\
\text { Diagnóstico }\end{array}$ & Manifestações patológicas \\
\hline $\begin{array}{l}\text { Oliveira et. al } \\
\text { (2013) }\end{array}$ & 40 anos & Urbana & $\begin{array}{c}\text { Inspeção } \\
\text { visual, ensaios } \\
\text { destrutivos e } \\
\text { não destrutivos }\end{array}$ & $\begin{array}{l}\text { Avançado nível de corrosão das } \\
\text { armaduras, carbonatação, alta } \\
\text { variabilidade no fck do } \\
\text { concreto }\end{array}$ \\
\hline $\begin{array}{c}\text { Souza et. al } \\
(2019)\end{array}$ & 50 anos & Urbana & $\begin{array}{l}\text { Inspeção } \\
\text { visual }\end{array}$ & $\begin{array}{l}\text { Corrosão da armadura, } \\
\text { fissuração, desplacamento do } \\
\text { concreto, manchas com } \\
\text { presença de microrganismos, } \\
\text { lixiviação, eflorescência e } \\
\text { infiltrações }\end{array}$ \\
\hline $\begin{array}{l}\text { Martins et. al } \\
\qquad(2016)\end{array}$ & 38 anos & Urbana & $\begin{array}{l}\text { Inspeção } \\
\text { visual }\end{array}$ & $\begin{array}{l}\text { Fissuras, manchas, corrosão da } \\
\text { armadura, desplacamento do } \\
\text { concreto, eflorescência } \\
\text { lixiviação }\end{array}$ \\
\hline $\begin{array}{l}\text { Lima et. al } \\
\text { (2010) }\end{array}$ & 30 anos & Urbana & $\begin{array}{l}\text { Inspeção } \\
\text { visual e } \\
\text { ensaios não } \\
\text { destrutivos }\end{array}$ & $\begin{array}{l}\text { Trincas, fissuras, surgimento de } \\
\text { vegetação, corrosão da } \\
\text { armadura, manchas de } \\
\text { umidade, } \\
\text { carbonatação e penetração de } \\
\text { cloretos }\end{array}$ \\
\hline $\begin{array}{l}\text { Araújo et. al } \\
\text { (2010) }\end{array}$ & 40 anos & $\begin{array}{l}\text { Respingos de } \\
\text { Maré }\end{array}$ & $\begin{array}{l}\text { Inspeção } \\
\text { visual, ensaios } \\
\text { destrutivos e } \\
\text { não destrutivos }\end{array}$ & $\begin{array}{l}\text { Desagregação do concreto, } \\
\text { corrosão das armaduras, } \\
\text { fissuras, manchas de } \\
\text { eflorescência, umidade (limo e } \\
\text { fuligem) e de oxidação. }\end{array}$ \\
\hline $\begin{array}{l}\text { Silva et. al } \\
\quad(2016)\end{array}$ & 40 anos & Urbana & $\begin{array}{l}\text { Inspeção } \\
\text { visual e } \\
\text { ensaios não } \\
\text { destrutivos }\end{array}$ & $\begin{array}{l}\text { Presença de bolor, manchas de } \\
\text { umidade, corrosão da armadura } \\
\text { e desplacamento do concreto }\end{array}$ \\
\hline
\end{tabular}




\begin{tabular}{c|c|c|c|l|}
\hline $\begin{array}{c}\text { Cirino et. al } \\
(2020)\end{array}$ & $\begin{array}{c}45 \text { anos } \\
\text { (aprox.) }\end{array}$ & Urbana & $\begin{array}{c}\text { Análise visual } \\
\text { e registro } \\
\text { fotográfico }\end{array}$ & $\begin{array}{l}\text { Corrosão das armaduras, } \\
\text { fissuras, desplacamento do } \\
\text { concreto e manchas de umidade }\end{array}$ \\
\hline $\begin{array}{c}\text { Couto et. al } \\
(2016)\end{array}$ & 56 anos & Urbano & $\begin{array}{c}\text { Inspeção } \\
\text { visual, ensaios } \\
\text { destrutivos e } \\
\text { não destrutivos }\end{array}$ & $\begin{array}{l}\text { Corrosão de armadura e } \\
\text { armadura flambada }\end{array}$ \\
\hline $\begin{array}{c}\text { Berenguer et. } \\
\text { al (2016) }\end{array}$ & 45 anos & Névoa Salina & $\begin{array}{c}\text { Inspeção } \\
\text { visual }\end{array}$ & $\begin{array}{l}\text { Corrosão das armaduras, } \\
\text { fissura, bolor, eflorescências e } \\
\text { manchas de umidade. }\end{array}$ \\
\hline $\begin{array}{c}\text { Torres et. al } \\
(2016)\end{array}$ & 58 anos & Urbana & $\begin{array}{c}\text { Inspeção } \\
\text { visual }\end{array}$ & $\begin{array}{l}\text { Trincas, sujidade } \\
\text { desplacamento da camada de } \\
\text { revestimento }\end{array}$ \\
\hline
\end{tabular}

Na tabela 2 estão dispostas as sínteses dos trabalhos analisados das edificações com idade inferior a 30 anos. Para cada autor foram catalogadas a idade da edificação, a classificação ambiental, os métodos de diagnósticos utilizados e as manifestações patológicas identificadas. Cabe destacar que o estudo desenvolvido por Araújo (2017) foi realizado em cinco escolas distintas, entretanto, na tabela a seguir foi apresentado um resumo com todas as manifestações patológicas identificadas pelo autor, considerando as cinco amostras. Para efeito de análise de resultados do presente estudo, cada uma das edificações apresentadas pelo autor fora considerada individualmente.

Tabela 2: Estudos de Caso com Idade Inferior a 30 anos.

\begin{tabular}{c|c|c|c|l}
\hline Autor & $\begin{array}{c}\text { Idade da } \\
\text { Edificação }\end{array}$ & $\begin{array}{c}\text { Classificação } \\
\text { Ambiental }\end{array}$ & $\begin{array}{c}\text { Método de } \\
\text { Diagnóstico }\end{array}$ & Manifestações Patológicas \\
\hline $\begin{array}{c}\text { Nadalini et. al } \\
(2017)\end{array}$ & 28 anos & Marítimo & $\begin{array}{c}\text { Inspeção } \\
\text { visual }\end{array}$ & $\begin{array}{l}\text { Corrosão das armaduras, } \\
\text { fissuração, desplacamento do } \\
\text { concreto e manchas. }\end{array}$ \\
\hline $\begin{array}{c}\text { Zenato et. al } \\
(2018)\end{array}$ & 3 anos & Urbano & $\begin{array}{c}\text { Inspeção } \\
\text { visual }\end{array}$ & $\begin{array}{l}\text { Corrosão das armaduras, } \\
\text { fissuração e carbonatação. }\end{array}$ \\
\hline $\begin{array}{c}\text { Araújo (2017) } \\
\text { anos }\end{array}$ & Urbano & $\begin{array}{c}\text { Inspeção } \\
\text { visual }\end{array}$ & $\begin{array}{l}\text { Corrosão das armaduras, } \\
\text { fissuração, manchas de bolor, } \\
\text { eflorescência. manchas de }\end{array}$ \\
\hline $\begin{array}{c}\text { Araújo et. al } \\
(2010)\end{array}$ & 5 anos & $\begin{array}{c}\text { Respingos de } \\
\text { maré }\end{array}$ & $\begin{array}{c}\text { Inspeção } \\
\text { visual, ensaios } \\
\text { destrutivos e } \\
\text { não destrutivos }\end{array}$ & $\begin{array}{l}\text { Fissuração, manchas } \\
\text { eflorescência, umidade e } \\
\text { acúmulo de limo, fuligem e de } \\
\text { oxidação }\end{array}$ \\
\hline
\end{tabular}

\section{RESULTADOS}

Todos os estudos de caso analisados utilizaram o método de diagnóstico por inspeção visual, sendo que 10 entre os 18 estudos selecionadas utilizaram exclusivamente este método para dar o diagnóstico das falhas identificadas. Na Figura 1-a estão os métodos de diagnóstico utilizados para identificação das manifestações patológicas nas estruturas com idade igual ou superior a 30 anos e na Figura 1-b estão os métodos utilizados nas estruturas com idade inferior a 30 anos. 
(a)

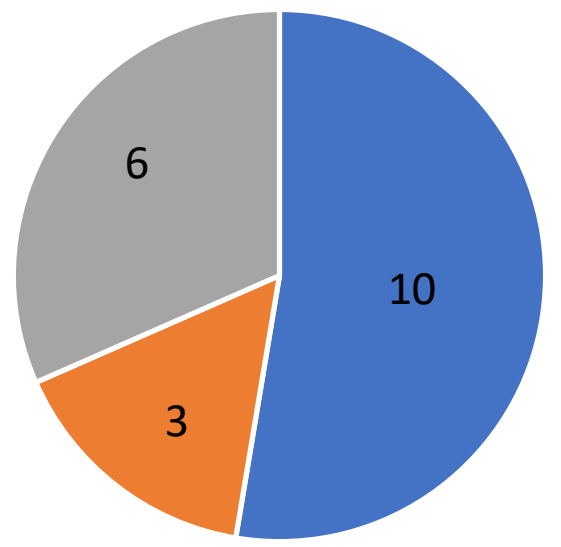

(b)

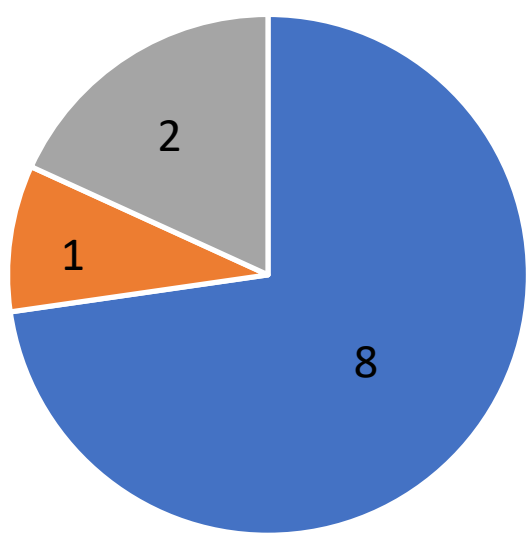

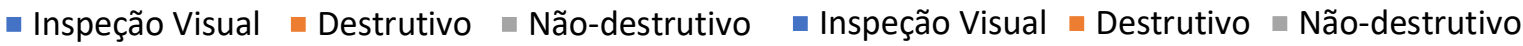

Figura 1. Métodos de diagnóstico edificações com idade $\geq 30$ anos (a) e com idade $<30$ anos (b).

Quando utilizados ensaios, o método de diagnóstico mais empregado foi o não-destrutivo, sendo utilizado em $44,44 \%$ dos estudos de casos analisados, onde foram realizados ensaios de teor de cloreto, resistividade elétrica, esclerometria, ultrassonografia, potencial de corrosão e profundidade de carbonatação. Em apenas quatro $(22,22 \%)$ dos casos analisados foram utilizados os métodos de diagnóstico destrutivo, para a extração de corpos de prova testemunhos.

Com relação à classe ambiental, mesmo muitos autores não fazendo referência à classificação estabelecida pela NBR 6118 (ABNT, 2014), descrevem o ambiente no qual as estruturas analisadas estão inseridas. Tendo em consideração essa descrição do ambiente, as edificações foram classificadas quanto a classe de agressividade ambiental estabelecida pela norma, sendo elas: moderada, quando inserida em ambiente urbano, forte, quando em ambiente marinho ou industrial e muito forte, quando possui respingos de maré. Na Figura 2-a estão expostas as classificações ambientais das edificações com idade igual ou superior a 30 anos e na figura 2-b a classificação das edificações com idade inferior a 30 anos.

(a)

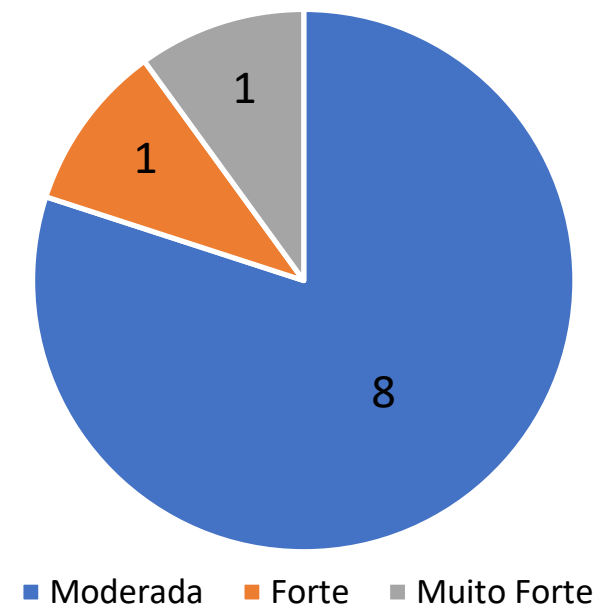

(b)

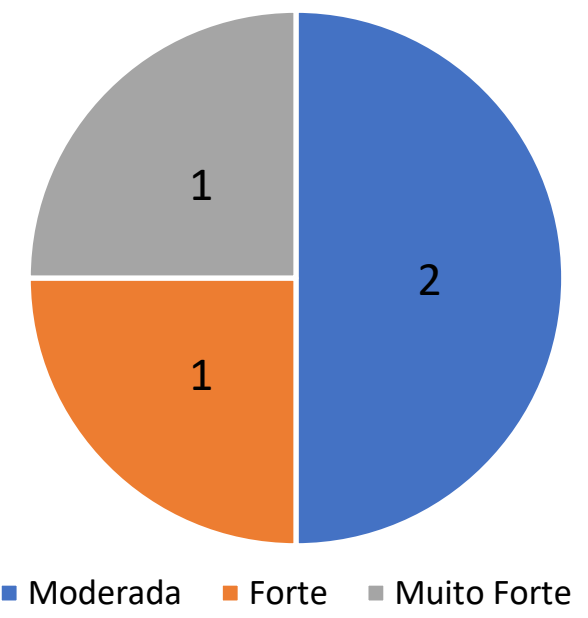

Figura 2. Classificação ambiental edificações com idade $\geq 30$ anos (a) e com idade $<30$ anos (b).

As manifestações patológicas identificadas nas edificações com idade superior a 30 anos, inseridas em ambientes com classificação forte e muito forte são a corrosão de armadura, fissuração, eflorescência, desplacamento do concreto e manchas. Já para as edificações com idade inferior a 30 anos, a manifestação patológica desplacamento de concreto foi identificada unicamente na 
edificação inserida em ambiente com névoa salina, ou seja, com classificação ambiental forte. Dentre as edificações analisadas não foi possível identificar uma relação entre o surgimento das manifestações patológicas com a classificação ambiental, pois nos dois grupos analisados, de edificações com idade igual e superior a 30 anos e com idade inferior a 30 anos, as manifestações identificadas nos ambientes classificados como forte e muito forte eram recorrentes em edificações inseridas na classificação ambiental moderada, com exceção da edificação com idade inferior a 30 anos inserida no ambiente com classificação ambiental forte, que apresentou desplacamento do concreto.

Entre os casos expostos pelos diferentes autores, para as estruturas com idade igual ou superior a 30 anos, é possível identificar que algumas manifestações patológicas são recorrentes entre os estudos analisados, como por exemplo a corrosão da armadura, as fissuras e as manchas. Já para as edificações com idade inferior a 30 anos, as manifestações patológicas de maior incidência são as fissuras, manchas e eflorescência, também não foram identificadas manifestações patológicas relacionadas à lixiviação e flambagem da armadura, para essas edificações. Ainda sobre as edificações com idade inferior a 30 anos, vale ressaltar o grande número de manifestações patológicas, que podem ser vinculadas a inferioridade de materiais utilizados, além de que ao uso de mão-de-obra pouco especializada, referindo-se a uma questão social importante ao nosso país. Na Figura 3 estão expostas as manifestações patológicas identificadas nas edificações com idade igual ou superior a 30 anos e com idade inferior a 30 anos.

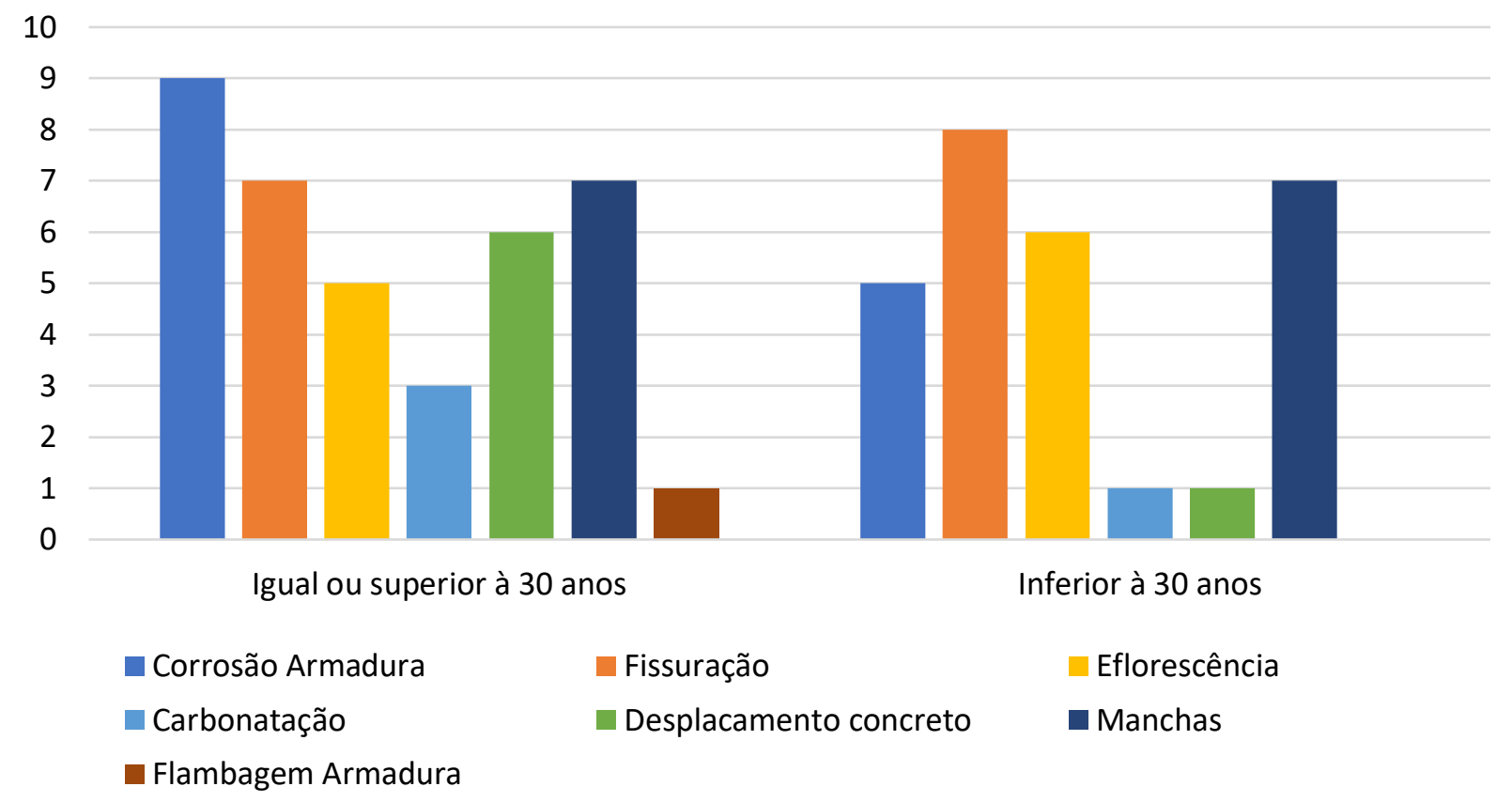

Figura 3. Manifestações patológicas identificadas.

Para a análise, foram catalogadas como manchas todas as manifestações patológicas relacionadas à sujidade, bolor, limo, mofo, umidade e fuligem. No item fissuração, foram considerados os relatos dos autores relacionados a fissuras e trincas.

As edificações analisadas possuíam uso residencial ou público, como universidades e departamentos, e um píer. Em apenas um estudo de caso não é identificado qual o uso da edificação. Quatro autores identificaram que o ambiente no qual a estrutura está inserida possui classe de agressividade forte a muito forte, sendo dois para as edificações classificadas com idade igual ou superior a 30 anos e dois para as edificações com idade inferior a 30 anos; os demais autores não identificam a classe de agressividade do ambiente no qual as edificações estão inseridas, sendo 
que, em sua maioria estão localizados em regiões urbanas e metropolitanas. Os trabalhos também não descrevem relações quanto às fachadas e posição solar das edificações.

Cabe ressaltar que em apenas um dos estudos de caso nas edificações com mais de 30 anos de idade os autores tiveram acesso aos projetos da edificação. Nas edificações com idade de uso inferior a 30 anos todos os autores tiveram acesso aos projetos das edificações.

Com relação ao processo de manutenção das estruturas durante sua vida útil, a maioria dos autores destacam que as manutenções realizadas nas edificações foram ineficientes, precárias ou que não houve nenhum tipo de manutenção preventiva durante seu uso. Com exceção de três estudos de casos, no qual não foi identificado se houve algum processo de manutenção durante a vida da edificação.

Algumas manifestações patológicas são mais recorrentes e que podem ter relação com a idade da edificação, como é o caso da corrosão da armadura e o desplacamento do concreto, manifestações estas que foram identificadas com frequência nas edificações com idade superior a 30 anos. Entretanto, foi possível identificar que algumas das manifestações patológicas como a fissuração, manchas e eflorescências são existentes tanto nas edificações consideradas jovens, quanto nas edificações com idade superior a 30 anos, o que implica que seu surgimento não está relacionado à idade de uso da estrutura ou com a vida útil dos materiais. Tais manifestações patológicas são passíveis de comparação entre os dois grupos de edificações com idades distintas, pois seu diagnóstico é realizado através do método de inspeção visual, o qual foi utilizado em todos os estudos analisados.

Por meio da análise é possível identificar que as edificações com idade igual ou superior a 30 anos, tendem à apresentar manifestações patológicas com um nível de complexidade superior ao das edificações com idade inferior a 30 anos, como é o caso da corrosão da armadura e o desplacamento do concreto, as quais necessitam de um grau de intervenção maior com técnicas e mão de obras especializadas para o correto tratamento da manifestação apresentada. Tal fator corrobora com as condições de vida útil estabelecidas pela NBR 15575 (ABNT, 2013), de que a estrutura possui um prazo pelo qual conserva as características e atribuições para a qual foi projetada.

Não foi identificada uma relação entre o surgimento das manifestações patológicas com a classificação ambiental, pois as edificações analisadas inseridas em ambientes agressivos apresentavam as mesmas manifestações patológicas que as edificações inseridas em ambientes com agressividade moderada. Apenas uma edificação, com idade inferior a 30 anos apresentou a manifestação patológica desplacamento de concreto, a qual estava inserida em ambiente com classificação ambiental forte, entretanto, a edificação apresentava idade de uso de 28 anos, próximo ao limite estabelecido para o grupo de edificações e, por se tratar de apenas uma edificação, não foi considerado como tendência o surgimento da manifestação patológica com a classificação ambiental.

\section{CONCLUSÕES}

Observou-se que grande parte dos estudos de casos desenvolvidos pelos autores ficam restritos à inspeção visual, não sendo realizados ensaios in loco ou laboratoriais como método de diagnóstico. Devido a esse fator algumas das manifestações patológicas, que são identificadas exclusivamente por meio de ensaios, como a carbonatação, podem existir, porém não são passíveis de identificação. Para as edificações com idade igual ou superior a 30 anos, a obtenção de dados referentes aos projetos é de difícil acesso. Em apenas um caso o autor teve acesso ao projeto da edificação, sendo essa edificação o píer, com maior complexidade, quando comparada as demais. Todos os autores que desenvolveram estudos de caso em edificações com idade inferior a 30 anos tiveram acesso aos projetos. 
Algumas manifestações patológicas identificadas em edificações com idade superior a 30 anos também são existentes em edificações consideradas jovens, o que indica que seu surgimento não está relacionado com a idade de uso ou com a vida útil dos materiais, como as fissuras, manchas e eflorescências. Também se observou que as edificações com idade superior a 30 anos apresentaram manifestações patológicas mais complexas e que necessitam de um tratamento especializado para sua correção, como é o caso da corrosão da armadura e desplacamento do concreto.

\section{REFERÊNCIAS BIBLIOGRÁFICAS}

ABNT - ASSOCIAÇÃO BRASILEIRA DE NORMAS TÉCNICAS. NBR 15575-1: Edificações Habitacionais - Desempenho - Parte 1: Requisitos Gerais. Rio de Janeiro: ABNT Editora, 2013.

ABNT - ASSOCIAÇÃO BRASILEIRA DE NORMAS TÉCNICAS. NBR 6118: Projeto de estruturas de concreto - Procedimento. Rio de Janeiro: ABNT Editora, 2014.

ARAÚJO, A. de; PANOSSIAN, Z. Durabilidade de Estruturas de Concreto em Ambiente Marinho: Estudo de caso. INTERCORR, ABRACO. Fortaleza/CE, 2010.

ARAÚJO, M. E. da S. O. Análise das Manifestações Patológicas em edificações escolares préfabricadas na cidade de Campinas/SP. 144f. Dissertação (Metrado em Engenharia Civil). Universidade Estadual de São Paulo. São Paulo, 2017.

BEBER, A. J. Comportamento Estrutural de Vigas de Concreto Armado Reforçadas com Compósitos de Fibra de Carbono. 289f. Tese (Doutorado em Engenharia). Universidade Federal do Rio Grande do Sul. Porto Alegre, 2003.

BERENGUER, R. A.; SIlvA, F. A. N.; MONTEIRO, E. C. B.; SIlVA, A. J. C. Recuperação estrutural do Ginásio de Esportes Geraldo Magalhães. Revista Concreto \& Construções, IBRACON, São Paulo, 2016.

CIRINO, M. A. G.; OlIVEIRA, B. B. de, PEREIRA, S. L. de O., CORDEIRO, S. B., MORAIS, J. M. P. de. Avaliação das Manifestações Patológicas das Edificações do Departamento de Engenharia de Alimentos da Universidade Federal do Ceará. Research, Society and Development, v. 9, n. 7, e481974424, 2020.

COUTO, D.; MIRANDA, D.; PACHECO, J. Retrofit da estrutura de um edifício com mais de 50 anos. Revista Concreto \& Construções, IBRACON, São Paulo, 2016.

COUTO, J. A. S.; CARMINATTI, R. L.; NUNES, R. R. A.; MOURA, R. C. A. O Concreto como Material de Construção. Cadernos de Graduação - Ciências Exatas e Tecnológicas. v. 1, n. 18, Sergipe, 2013.

FÉDÉRATION INTERNATIONALE DU BETÓN. Structural Concrete: Textbook on behavior, design and performance. Lausanne, 1999 (Bulletins 1, 2, 3).

LIMA, S. M. de; SIQUEIRA, W. G. Manifestações Patológicas em Laje de Cobertura: Estudo de Caso. VI Congresso Internacional sobre Patologia e Reabilitação de Estruturas. Córdoba, Argentina, 2010. 
LOPES, S. L. Patologias em Construções que Utilizam Concreto Armado e Técnicas de Reparo e Manutenção. Revista Científica da Faculdade de Educação e Meio Ambiente - FAEMA, Ariquemes, v. 10, n. 1, p. 23-33, jan-jun. 2019.

MARTINS, J. F. A.; FIORITI, C. F. Investigação de Manifestações Patológicas em Sistemas Estruturais de Concreto Armado: Estudo de Caso em Edificação Pública. Revista Brasileira de Iniciação Científica, Itapetininga, v. 3, n. 4, 2016.

NADALINI, A. C. V.; BISPO, A. O. Patologia em Estruturas de Concreto Armado em Ambiente Marítimo. XIX COBREAP - Congresso Brasileiro de Engenharia de Avaliações e Perícias, Foz do Iguaçu, 2017.

OliVEIRA, K. C. de; HelenE, P.; CARROMEU, C. C.; COUTO, D. de A.; BILESKY, P.; SAMPAIO, M. R. A. de. Extensão da Vida Útil de uma Estrutura de Concreto Armado dos Anos 60. Revista Concreto \& Construções, IBRACON, São Paulo, 2013.

PASSOS, L. B; CARVAlHO, I. P. G.; ARAÚJO, L. S. O; BRAGA, J. H. F. J. Ensaios não Destrutivos na Avaliação de Estruturas de Concreto. Revista Concreto \& Construções, IBRACON, São Paulo, 2019.

SANTOS, R. E. Armação do Concreto no Brasil: História da difusão da tecnologia do concreto armado e da construção de sua hegemonia. Tese (doutorado) - Pós-graduação em Educação, Universidade Federal de Minas Gerais, Belo Horizonte, 2008.

SENA, G. O. de; NASCIMENTO, M. L. M.; NETO, A. C. N.; LIMA, N. M. Patologia das Construções. Salvador: Editora 2B, 2020.

SILVA, M. T. de A.; SILVA, A. C. da; SANTOS, C. F. dos; ROCHA, J. H. A.; COSTA, C. F. B.; MONTEIRO, E. C. B. Análise do Estado de Conservação de uma Marquise de Edificação Residencial por Meio de Ensaios de Ultrassom: Um Estudo de Caso. I Seminário de Patologia e Recuperação Estrutural-SEMIPAR, UPE, Recife, 2016.

SOUZA, L. S.; LIMA, H. J. N. de. Análise de Manifestações Patológicas e Reparo em Edifício de Concreto Armado - Estudo de Caso. Revista Interscientia, v. 7, n. 2, p. 27-40, 2019.

SOUZA, V. C. M.; RIPPER, T. Patologia, recuperação e reforço de estruturas de concreto. $1^{\mathrm{a}}$ ed., $5^{\mathrm{a}}$ triagem. São Paulo: Editora PINI, 2009.

TORRES, A. S.; SILVA, V. M. B.; PALIGA, C. M. Análise das Manifestações Patológicas em Reservatórios Elevados na Cidade de Pelotas/RS. REEC - Revista Eletrônica de Engenharia Civil, v.12, n. 1, p. 12-22, 2016.

TUTIKIAN, B.; PACHECO, M. Inspeção, diagnóstico e prognóstico na construção civil. Asociación Latinoamericana de Control de Calidad, Patología y Recuperación de la Construcción - ALCONPAT, 2013.

ZENATO, C.; SILVA, C. R.; DANIELESKI, C. B.; ROTH, P. T.; FERRARO, R.; TUTIKIAN, B. F. Determinação de vida útil residual de estruturas de concreto de edifício residencial multifamiliar. Revista Concreto \& Construções, IBRACON, São Paulo, 2018. 